\title{
ТАКСИС И КОНДИЦИОНАЛЬНОСТЬ В АСПЕКТЕ ПОЛИКАТЕГОРИАЛЬНОГО СИНКРЕТИЗМА
}

\section{TAXIS AND CONDITIONALITY IN THE ASPECT OF POLY-CATEGORICAL SYNCRETISM}

\section{Arkhipova}

Summary: The article discusses the functional-semantic categories of taxis and conditionality in the aspect of poly-categorical syncretism in complicated polypropositive sentences with prepositional deverbatives. In statements with prepositional deverbatives, aspectual-taxic categorical situations with the semantics of conditionality are actualized. Conditional-taxis values are represented in statements of the sub-field of the second taxis with taxis-forming prepositions bei, in, unter in the conditional value. The prototypical semantic components of the conditional-taxis syntagmatic context are the conditional actualizers and the monosubjectivity or polysubjectivity of the propositions with prepositional deverbates.

Keywords: functional-semantic category, functional-semantic field, polycategorical syncretism, taxis, conditionality, conditional-taxis categorical situations, conditional actualizers.
$\mathrm{B}$ статье рассматривается вопрос межкатегориального синкретизма двух функционально-семантической категорий: таксиса и кондициональности. Поликатегориальный субкомплекс, конституируемый функционально-семантическими категориями таксиса и кондициональности (кондиционально-таксисный субкомплекс-термин И.В. Архиповой), предлагается рассматривать в рамках предлагаемой нами вслед за выдающимся отечественным лингвистом А.В. Бондарко модели аспектуально-темпорально-таксисного поликатегориального комплекса. Базовым термином послужил термин А.В. Бондарко «аспектуально-темпоральный комплекс», трактуемый как группировка функционально-семантических полей (ФСП) и соответствующих категориальных ситуаций (аспектуальности, темпоральности, временной локализованности, таксиса и временного порядка) [10, с. 96].

Категория таксиса дефинируется как полицентрическое (бицентрическое) функционально-семантическое поле (ФСП), формируемое взаимодействующими друг с другом языковыми единицами разных уровней (морфологического, лексико-грамматического, синтаксического) $[1 ; 2 ; 3 ; 4 ; 5 ; 6 ; 7 ; 10]$. Функционально-семантическое поле кондициональности (ФСП) рассматривается современными исследователями на материале разноструктурных языков (русского, болгарского, татарского,

\author{
Архипова Ирина Викторовна \\ к.филол.н., профессор, Новосибирский государственный \\ педагогический университет \\ irarch@yandex.ru
}

Аннотация: В статье рассматриваются функционально-семантические категории таксиса и кондициональности в аспекте поликатегориального синкретизма в осложненных полипропозитивных высказываниях с предложными девербативами.

В высказываниях с предложными девербативами актуализируются аспектуально-таксисные категориальные ситуации с семантикой кондициональности. Кондиционально-таксисные значения репрезентируются в высказываниях субполя секундарного таксиса с таксисообразующими предлогами bei, in, unter в кондициональном значении. В качестве прототипичных семантических компонентов кондиционально-таксисного синтагматического контекста выступают кондициональные актуализаторы и моносубъектность или полисубъектность высказываний с предложными девербативами.

Ключевые слова: слова: функционально-семантическая категория, функционально-семантическое поле, поликатегориальный синкретизм, таксис, кондициональность, кондиционально-таксисные категориальные ситуации, кондициональные акутализаторы.

чувашского, немецкого, английского и др.) [8; 9; 11; 12; $13 ; 14 ; 15 ; 16 ; 17 ; 18 ; 19]$. ФСП кондициональности имеет полицентрическую структуру и репрезентируется взаимодействующими друг с другом языковыми средствами (морфологическими, словообразовательными, лексическими, грамматическими, синтаксическими), объединенными единой семантической функцией условия (кондициональности).

Предложение с кондициональной семантикой представляет собой бипропозитивную семантическую структуру, включающую: (а) «условие», обозначающее семантически независимую пропозицию и (б) «следствие», обозначающее семантически зависимую пропозицию [9, с. 7-8]. Е.В. Селезнева выделяет в этой связи обусловливающее событие (ситуацию) и обусловливаемую ситуацию $[17$, с. 6]. Современными исследователями называется два вида условия: гипотетическое (потенциальное/ ирреальное) и реальное. Реальное условие (в отличие от гипотетического) предполагает, что обусловливающая ситуация реализована или реализуется [17, с. 5-6]. В этой связи Н.А. Давыдова на материале английского языка выделяет микрополе реального условия, микрополе гипотетического условия и микрополе нереального условия [11, с. 21]. В качестве языковых средств репрезентации кондициональной семантики выступают: предлоги, союзы, глагольные формы, предложно-падеж- 
ные формы, порядок следования условных конструкций, лексические квалификаторы условных отношений только, лишь, даже, особенно, тем более, erst, nur, aber и др. $[9$, с. $8 ; 17$, с. 8$]$.

Разноуровневые языковые средства (лексические, грамматические, синтаксические и др., в том числе комбинированные) репрезентируют семантику кондициональности в моно-, полу- и полипредикативных полипропозитивных высказываниях, т.е. в простом, осложненном и сложном предложениях в разноструктурных языках. К ним относятся сложноподчиненные союзные предложения (с условными и условно-темпоральными союзами wenn, falls, sofern, if, in case, unless, in case, lest, as long as, so long as, suppose that, supposing that, on condition that, provided that, provoding that, but for, если, когда, коли, ежели, в случае если, при случае если, при условии если и др.); бессоюзные предложения с семантикой условия; сложносочиненные предложения с кондициональной семантикой с союзами und, aber, oder, dann, doch, denn, sonst; простые осложненные предложения с различными кондициональными или кондиционально-темпоральными предлогами bei, unter, in, при и др.; деепричастные, причастные, инфинитивные и герундиальные конструкции; условные конструкции на основе предложно-именных сочетаний типа при условии, в случае/nри случае/на случай, unter der Voraussetzung, im Falle, unter der Bedingung в разноструктурных языках.

Все высказывания с кондициональными конструкциями характеризуются различной степенью прототипичности, регулярности употребления и «центральности». Центральные (ядерные) компоненты ФСП кондициональности характеризуются эксплицитным характером репрезентации кондициональной семантики, а периферийные конституенты - имплицитным характером и межкатегориальным синкретизмом кондициональности и темпоральности или каузальности и др. Центр ФСП кондициональности конституируют синтаксические структуры на базе сложноподчиненных предложений условной семантики, а к периферии относятся условные конструкции с лексико-грамматическими средствами, в том числе, с лексическими квантификаторами или актуализаторами кондициональных отношений.

В аспекте межкатегориального синкретизма функционально-семантической категории таксиса и категории кондициональности в высказываниях с предложными девербативами актуализируется аспектуально-таксисные значения с элементами обстоятельственной (секундарной, вторичной, сопутствующей) семантики кондициональности. Кондиционально-таксисные значения одновременности актуализируются в высказываниях субполя секундарного (вторичного, обстоятельственного, сирконстантного, фонового, логически обусловленного) таксиса, содержащих девербативы с таксисообра- зующими предлогами bei, in, unter в кондициональном значении:

Mit diesem jungen Manne, einem Herrn Mack, wurde, unter unbedingter Zustimmung des Onkels, besprochen, gemeinsam um halb sechs Uhr fru

Кроме того, в высказываниях с предложными деверабативами на имплицитную кондициональную семантику могут указывать такие элементы кондиционально-таксисной среды, как: (1) модальные глаголы; (2) отрицание nicht; (3) формы настоящего и будущего времени; (4) формы конъюнктива. Например:

Beim Betrachten des Meeres aus der Ferne kann man sich nun vorstellen, wie es sich anfühlt, die Schuhe auszuziehen und die Füße in den heißen Sand sinken zu lassen. (www. adz.ro, gecrawlt am 26.03.2018).

Beim Betrachten kann es einem schwindelig werden. (www.faz.net, gecrawlt am 25.03.2018).

In der letzten Folge konnte man beim genauen Hinhören auch Anspielungen und Hinweise auf den Ausgang des Finales entdecken. (www. kreiszeitung. de, gecrawlt am 25.03.2018)

Bei genauem Hinhören tut er genau das nicht. (www.taz. de, gecrawlt am 29.03.2018)

Прототипическим признаком актуализации кондиционально-таксисных значений одновременности в высказываниях с предлогом bеi в кондициональном значении является их моносубъектность, т.е. наличие одного субъекта соотносимых между собой во времени действий девербатива и глагольного предиката. Ср.:

Beim Zusehen dachte ich, ich würde alles, aber auch alles dafür geben, wenn ich so tanzen könnte. (www.woz.ch, gecrawlt am 26.03.2018).

Erst beim Hinausgehen realisiere ich, dass ich anderthalb Stunden mit einem Briten über Europa geredet habe ... (bazonline.ch, gecrawlt am 27.03.2018).

Erst bei näherem Hinsehen erkennt der Betrachter den wahren Wert seiner Arbeiten. (www.faz.net, gecrawlt am 26.03.2018).

Синкретизм темпоральных, кондициональных и каузальных значений наблюдается в следующих высказываниях в силу их кондиционально-темпоральной (в частности, при отсутствии актуализаторов кондициональности) и кондициональной или каузальной семантики и в связи с их соответствующим лексико-семантическим наполнением. Например:

Beim Anschauen der Erinnerungsfotos aus der Schulzeit wurde sich über Aussehen und Kleidung von damals 
köstlich amüsiert. (www.wort.lu, gecrawlt am 28.03.2018).

Da läuft einem schon beim Zusehen das Wasser im Mund zusammen. (www. grenchnertagblatt.ch, gecrawlt am 26.03.2018)

Bei diesem putzigen Anblick ist es wirklich schwer, noch länger gestresst und ärgerlich zu sein. (www.stuttgarterzeitung.de, gecrawlt am 27.03.2018).

В приведенных выше моносубъектных высказывани- ях актуализируются сопряженные кондиционально-каузально-таксисные категориальные ситуации одновременности (полной, частичной).

Кроме того, в полисубъектных высказываниях с предлогом unter в кондициональном значении актуализируются синкретичные темпорально-кондициональнотаксисные значения одновременности. Ср.:

Unter dem warmen Rauschen des Wassers kamen die verstц

\section{ЛИТЕРАТУРА}

1. Архипова И.В. Высказывание с предложными девербативами в современном немецком языке: монография. Новосибирск: НГПУ, 2012.148 с.

2. Архипова И.В. Предложные девербативы в современном немецком языке: монография. Новосибирск: НГПУ, 2013.80 с.

3. Архипова И.В. Предложный девербатив как конституент зависимого таксиса современного немецкого языка // Вестник Новосибирского государственного педагогического университета. 2016. № 4. С. 135-142.

4. Архипова И.В. Обстоятельственные таксисные ситуации в современном немецком языке // Евразийский гуманитарный журнал. 2019. № 2. С. 89-93.

5. Архипова И.В. Синкретизм в сфере актуализации таксисных значений одновременности // Современная наука: актуальные проблемы теории и практики. Серия «Гуманитарные науки», -2019. № 12-2,-С. 149-154.

6. Архипова И.В. Функциональный потенциал девербативов и его реализация в контексте // Евразийский гуманитарный журнал. 2020. № 1. С. $74-87$.

7. Архипова И.В. Модель функционально-семантического поля таксиса // Современная наука: актуальные проблемы теории и практики. Серия «Гуманитарные науки», -2020. -№ 1. -С. 131-137.

8. Акимова Т.Г., Козинцева Н.А. Условные предложения в английском языке// Типология условных конструкций. Отв. ред. В.С. Храковский. СанктПетербург: Наука, 1998. С.306-324.

9. Ашрапова А.Х. Функционально-семантическое поле кондициональности в разноструктурных языках: Автореф. дис. ... канд. филол. наук. Казань, 2006. 22 с.

10. Бондарко А.В. Категоризация в системе грамматики. М.: Языки славянских культур, 2011. 488 с.

11. Давыдова Н.А. Репрезентация условных отношений в английском дискурсе: Автореф. дис. . .. канд. филол. наук. М., 2006. 24 с.

12. Евстафиади 0.В. Актуализаторы имплицитных условных отношений в художественном тексте на английском языке // Известия Самарского научного центра Российской академии наук. 2010. Т. 12. № 3. С. 157-162.

13. Завгородняя Е.В. Структурно-семантические особенности условных конструкций на различных ярусах синтаксиса современного русского языка: Автореф. дис. ... канд. филол. наук. Ставрополь, 2000. 25 с.

14. Кострова О.А. Средства выражения условных отношений в немецком языке: Автореф. дис. . .. канд. филол. наук. Ярославль, 1971. 18 с.

15. Кибардина С.М. Условные конструкции в немецком языке // Типология условных конструкций. Отв. ред. В.С. Храковский. СПб.: Наука, 1998. С. $297-305$.

16. Л.П. Функциональная категория условия-следствия в современном немецком языке: Автореф. дис. ... канд. филол. наук. М., 1988. 22 с.

17. Селезнева Е.В. Сложноподчиненные предложения, выражающие условные отношения (на материале русского и английского языков): Автореф. дис. ... канд. филол. наук. Воронеж, 2011. 24 с.

18. Храковский В.С. Теоретический анализ условных конструкций (семантика, исчисление, типология) // Типология условных конструкций. Отв. ред. В.С. Храковский. СПб.: Наука, 1998. С.7-96.

19. Шустер А.Г. Категория следствия и средства ее реализации на разных ярусах синтаксиса в современном немецком языке: Автореф. дис. ... канд. филол. наук. Ставрополь, 2005. 20 c. 